\title{
Cell-based Research and Therapy for Amyotrophic Lateral Sclerosis: Promises and Challenges
}

\author{
Juliana Ferreira Vasques ${ }^{1,2,4,5} \bullet$ Leandro Coelho Teixeira Pinheiro ${ }^{1,2,4,5} \bullet$ \\ Renata Guedes de Jesus Gonçalves, ${ }^{1,2,4,5} \bullet$ Rosalia Mendez-Otero ${ }^{1,2,4,5} \bullet$ \\ Fernanda Gubert 2,3,4,5 \\ ${ }^{1}$ Instituto de Biofísica Carlos Chagas Filho, Universidade Federal do Rio de Janeiro, Brazil; \\ ${ }^{2}$ Instituto Nacional de Ciência e Tecnologia em Medicina Regenerativa, Brazil; ${ }^{3}$ Instituto de \\ Ciências Biomédicas, Universidade Federal do Rio de Janeiro, Brazil; ${ }^{4} \mathrm{RJ}$ Nanotechnology \\ Research Networks Program, Brazil; ${ }^{5}$ Translational/Clinical Research Network on \\ Neurodegenerative Diseases, Brazil.
}

Author for Correspondence: Juliana Ferreira Vasques, Instituto de Biofísica Carlos Chagas Filho, Universidade Federal do Rio de Janeiro, Brazil. Email: julianavasques@biof.ufrj.br Doi: https://doi.org/10.36255/exonpublications.amyotrophiclateralsclerosis. celltherapy.2021

\begin{abstract}
Amyotrophic lateral sclerosis (ALS) is a fatal neurodegenerative disease which leads to a progressive degeneration of motoneurons. Since the pharmacological options available provide only a slight increase in life expectancy, cell therapy is emerging as a promising therapeutic alternative for ALS. A growing body of evidence from studies using genetically engineered ALS animal models demonstrate the safety and efficacy of therapies based on different cell types such as mononuclear cells, neural progenitors, and mesenchymal stem cells. Despite the encouraging results in preclinical studies, cell therapy-based clinical trials for ALS have achieved only modest results so far, probably due to the genotypic variations seen among ALS patients, which is difficult to reproduce in animal models.
\end{abstract}

In: Amyotrophic Lateral Sclerosis. Araki T (Editor), Exon Publications, Brisbane, Australia. ISBN: 978-0-6450017-7-8. Doi: https://doi.org/10.36255/exonpublications. amyotrophiclateralsclerosis.2021

Copyright: The Authors.

License: This open access article is licenced under Creative Commons Attribution-NonCommercial 4.0 International (CC BY-NC 4.0) https://creativecommons.org/licenses/by-nc/4.0/ 
The advent of induced pluripotent stem cells (iPSCs) has enabled the development of patient-specific cell lines, a valuable tool to investigate in vitro molecular mechanisms of the disease and therapies in different genetic backgrounds. The applications of ALS iPSCs and their future therapeutic potential are also briefly discussed in this chapter.

Keywords: amyotrophic lateral sclerosis; cell therapy; induced pluripotent stem cells; mesenchymal stem cells; stem cells

\section{INTRODUCTION}

Amyotrophic lateral sclerosis (ALS) is a fast-progressing neurodegenerative disease that affects motoneurons and results in neuronal death. Although neuronal death is the hallmark of the disease, non-neuronal cells such as astrocytes and microglia play an important role in disease progression (1). Although much progress has been made in the comprehension of ALS pathophysiology, only Riluzole and Edaravone are approved by the FDA (Food and Drug Administration) and have a modest increase in the survival time (2). Cell therapy is emerging as a promising strategy to treat ALS. Several cell types have been suggested, including stem and progenitor cells, and adult somatic cells from different sources, with or without genetic modifications (Figure 1).

Stem cells are defined as cells capable of self-renewal and differentiation into more than one cell type. They are classified as totipotent, pluripotent or multipotent, depending on differentiation capabilities. Totipotent stem cells are the zygotes, that could form the whole individual, while pluripotent stem cells are capable of forming cells from the three germ layers: as embryonic stem cells (ESCs) and induced pluripotent stem cells (iPSCs). Multipotent stem cells generate only cells from a specific linage or tissue, such as neural stem cells (NSCs) or mesenchymal stem cells (MSCs).

Many factors must be considered to decide the most appropriate cell therapy for a given patient. The clinical problem and the tissue that must be repaired are the primary factors. Cell therapy may aim to regenerate cells or tissue, and in this case pluripotent or multipotent stem cells from the tissue of interest could be used to replace the lost cells. However, cell therapy could also be used to favor the damaged tissue survival or regeneration. MSCs, for example, release paracrine factors that protect host cells that are degenerating, reduce inflammation, stimulate angiogenesis, among others (3). In practice, each stem cell has its advantages and disadvantages for clinical application. For example, ESCs have the advantage of indefinitely proliferation and broad capacity for differentiation but are prone to form tumors or differentiate uncontrollably into undesirable cell types. These cells are of allogeneic origin, requiring immunosuppression when transplanted. iPSCs could overcome this last limitation, once they can be derived directly from the patient. Unfortunately, it is still expensive and time consuming to produce patientspecific iPSCs for therapy. In addition, for diseases such as ALS in which genetic mutations are involved, autologous cell therapy is not the best choice. Multipotent stem cells, that comprises MSCs, could be used autologously, avoiding immunological concerns. However, stem cells from adult tissue are usually present in 


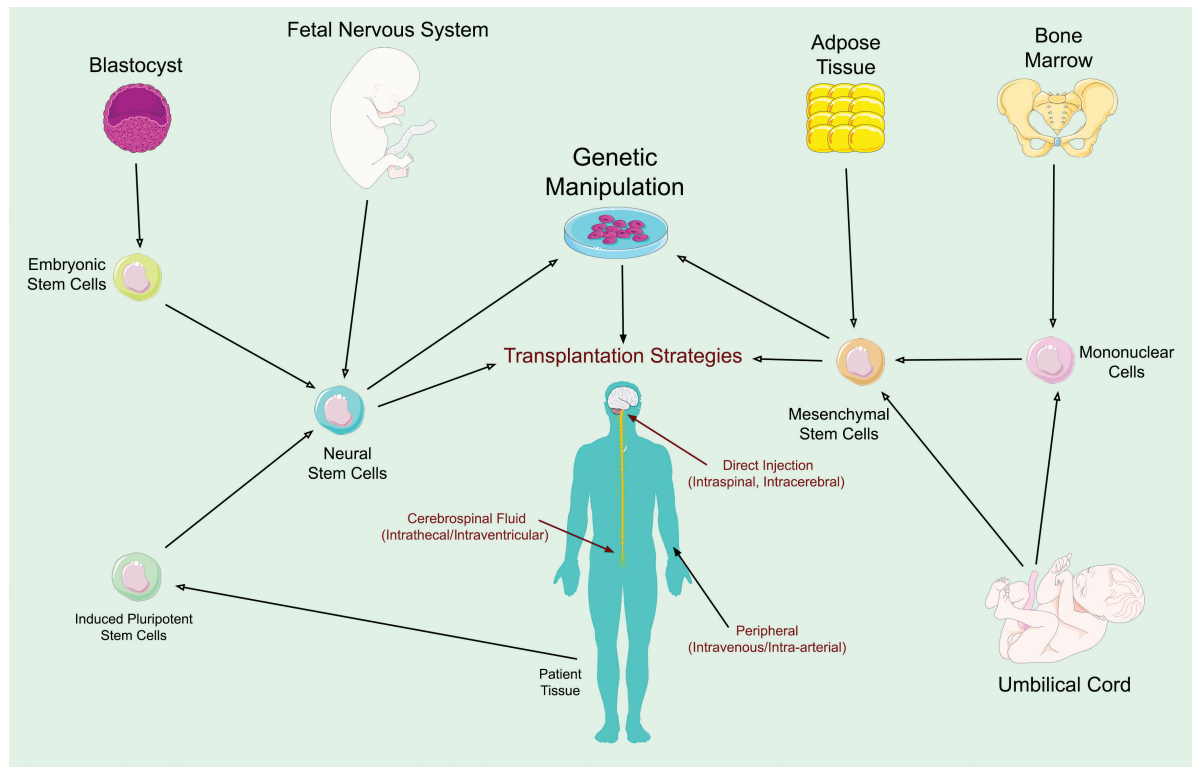

Figure 1. Therapeutic strategies using cells in ALS. Neural stem cells from different sources could be used to replace motoneurons or glial cells, while mesenchymal stem cells or mononuclear blood cells have been tested mainly as immunomodulators. Genetic manipulations, such as growth factors superexpression, can improve cells therapeutic potential. Created using https://smart.servier.com/.

limited quantities and have slow expansion rate, hindering autologous use for the treatment of acute illnesses or traumas, which require immediate treatment. In addition, the number of adult stem cells in most tissues appears to decrease with age (4). In this chapter, the use of cell therapy in ALS is discussed. Different cell types tested in ALS preclinical models and clinical trials are reviewed. Their limitations, and strategies to overcome these limitations are described.

\section{CELL THERAPY IN ALS PRECLINICAL MODELS}

Different cell types, doses, and administration routes have been tested in ALS preclinical models, with variable outcomes. The most used cell types in these studies are mononuclear cells, MSCs and NSCs. The main findings of these therapeutic strategies are discussed in the following sections.

\section{Mononuclear cells}

The first cell therapy test aimed to replace bone marrow of ALS mice with mononuclear cells from wild-type mice bone marrow or from human umbilical 
cord (5-7). Mononuclear cells are a heterogeneous population that comprise both hematopoietic stem cells and MSCs, as well as hematopoietic progenitors, lymphocytes and monocytes. At that time, some groups suggested that ALS could be an autoimmune disease and therefore, such replacement could alter the disease progression (5). Using this approach, Corti and co-workers showed increased animal survival and motoneuron protection, while Solomon and co-workers did not observe alteration in disease evolution despite observing transplanted cells in the spinal cord $(6,7)$. Other studies suggested that the number of hematopoietic stem cells present in each mononuclear fraction transplanted could be the reason for variable outcomes (5-8). Despite the contradictory results, the use of mononuclear cells continued to be tested, focusing mainly in neuroinflammation modulation (8).

Neuroinflammation has been shown to be an important process in disease pathology. Microglia, astrocytes, and lymphocytes have major roles in ALS (1). Therefore, cell therapy could act as an immunomodulator, ultimately resulting in neuroprotection. Intravenous injection of mononuclear cells derived from human umbilical cord (hUCB-MCs) in a mice model of ALS reduced disease progression and increased lifespan, even when the cells were administrated after the onset of the disease $(9,10)$. This approach decreased microglia density in spinal cord, reduced pro-inflammatory cytokines in the central nervous system, and increased lymphocytes and decreased neutrophils in peripheral blood, suggesting that hUCB-MC therapy could result in motoneuron neuroprotection by modulation of host inflammatory response (9). Interestingly, hUCB-MCs administrated intracerebroventriculary in murine ALS model also showed positive outcomes. However, transplanted cells were not found in the spinal cord, corroborating the hypothesis that injected cells do not necessarily need to be at the injury site to have a beneficial role (11).

Bone marrow mononuclear cells (BM-MCs) were also tested in mouse models of ALS. Although they are similar to UCB-MCs, BM-MCs can be used autologously, avoiding immunosuppression. Using BM-MCs, different injection routes, such as intraspinal, intramuscular, and intravenous, were tested (12-14). Therapies using these routes individually showed modest positive outcomes, but combined transplantation routes were able to delay disease progression and decrease microgliosis, although there was no change in lifespan $(13,14)$. These results are in agreement with the multifactorial profile of ALS, suggesting that an intervention in multiple pathways is necessary. In addition, BM-MC therapy in mice model only show positive results when administrated in the presymptomatic phase, an issue that could compromise translation to the clinic (12).

\section{Mesenchymal stem cells}

MSCs are part of the pool of cells harvested from bone marrow. Despite representing only $0.001 \%$ to $0.01 \%$ of total cells (15), MSCs have been extensively studied as key contributors of positive therapeutic effects of BM-MCs. MSCs are versatile cells that strongly respond to different environments, shifting an important paracrine activity that impacts neighboring cells. Therapeutic effects of MSCs are considered to be mostly paracrine, by their ability to secrete a wide variety of growth factors, cytokines, hormones, extracellular vesicles and even mitochondria, that 
can act locally or systemically. MSCs also have practical advantages to be used in a clinical setting. They can be harvested from tissues such as bone marrow and adipose tissue for autologous transplantation, or can be isolated from umbilical cord, placenta, dental pulp, and other tissues that are often discarded, and used in allogeneic therapies, since they are low immunogenic (3). They can be expanded in vitro and stored in large amounts in biobanks, ready to use when necessary (3). To narrow the types of cells harvested from these tissues, the International Society for Cellular Therapy has defined minimal criteria for MSC characterization (16).

Preclinical studies of MSC therapy for ALS are primarily based on transgenic mice and rats with SOD1 mutations. Despite being a model that genetically represents only a small portion of ALS patients, it recapitulates critical hallmarks of motoneuron degeneration such as axonal degeneration, apoptosis, and accentuated gliosis (17). These studies vary in their therapeutic approach, testing different MSCs sources, allogenic or xenogeneic origin, therapeutic window, administration routes and dosages.

MSC therapy for ALS relies mostly on it effects directly on motoneurons and/ or indirectly on glial and immune cells. MSCs produce and secrete a wide variety of growth factors and cytokines known to be protective to motoneurons, such as GDNF, IGF-1, BDNF, NGF and VEGF (18). For this reason, many preclinical studies injected MSCs directly into the spinal cord, hoping to increase the availability of these factors to motoneurons. After allogenic transplantation at the onset of disease in rats, cells remain in the injection site until end stage of the disease, improving motor capacity, motoneuron survival and increasing lifespan (19), while human MSCs injected long before symptoms onset in mice were no longer detected 70 days after injection, improving motor performance without effect on neuron protection and animals' survival (20). Thus, these data indicate that integration of MSCs to the target tissue can impact therapy outcome.

A less invasive approach to make MSCs secretome available to the spinal cord is delivering cells in the cerebrospinal fluid (CSF) by intrathecal or intracisternal injection. Injected in the CSF, MSCs were shown to survive in the spinal cord (21), spread through the ventricular system reaching the brain (22), and even differentiate into astrocytes (23). Moreover, MSCs reduced astrogliosis, microglia proliferation and inflammation in the spinal cord (21, 23-26). However, systemic administration (less invasive than intrathecal or intracisternal) of MSCs can also reduce inflammation in the spinal cord with limited homing in neural tissue (27), reducing oxidative and glutamatergic stress (28) and increasing neurotrophic factors production by glia (29). The mechanisms by which systemically injected MSCs exert effects in the CNS are still not clear. Terashima and colleagues (30) demonstrated that systemic administration of MSCs expressing HGF, GNDF and IGF-1 were also able to induce the expression of chemoattractants in the spinal cord, increasing the homing of injected bone marrow cells to this tissue.

Given the wide range of approaches to test the effect of MSCs, Zhou and colleagues performed a systematic review and meta-analysis of ALS preclinical studies using these cells. They included 25 studies published until July 2019 and found that MSC therapy in general delayed the age of disease onset, improved motor function, increased lifespan and reduced the estimated hazard ratio for disease. They also analyzed the effect of the different therapeutic approaches. However, given the diversity of the parameters among studies, they found no significant indication of advantage of any specific parameter. However, they point 
to an indication to greater benefit of presymptomatic treatments, adipose tissue derived MSCs, and a better general response to treatment in female subjects.

\section{Neural stem cells}

While the preclinical studies using MSCs in the presymptomatic stage show a good perspect for future ALS therapies as described above, in the clinical setting, most patients receive their diagnosis long after the appearance of symptoms, indicating that significant motoneuron death has already occurred. Considering this situation, neural stem cells (NSCs) from fetal tissue or induced from ESCs and iPSCs would be an alternative to replace lost motoneurons. Transplanted NSCs were shown to integrate into ALS spinal cord and differentiate into neurons with functional synapses, improving motoneuron survival and motor function (31). However, a newly formed motoneuron in an adult human would have to extend their axon out of the spinal cord to a specific muscle target, and while few studies demonstrated the feasibility of this approach (32), this was not yet demonstrated in ALS models.

Considering that the loss of motoneurons in ALS is not entirely due to cell intrinsic mechanisms, but also due to glial and systemic signaling, this hostile environment would also be detrimental to newly formed neurons. In this context, NSCs can also be used as a source of protective cells, as astrocytes and interneurons that secrete growth factors and act as mediators to reduce local inflammation. NSCs can be induced to produce glial derived trophic factors such as GDNF (33) and differentiate into astrocytes (34). Thomsen and colleagues (35) demonstrated that human NSCs expressing GDNF transplanted into the cortex of ALS rats can improve symptoms and extend survival after differentiating into astrocytes, and they have also demonstrated that these cells can be safely transplanted into the cortex of cynomolgus monkeys (Macaca fascicularis), showing a similar pattern of astrocyte differentiation. While the prospect to use NSCs to replace motoneurons is still far away, the use of these cells to generate glia shows a great therapeutic potential in the near future.

\section{CLINICAL TRIALS USING STEM CELLS IN ALS}

A variety of cells, doses, and delivery routes/sites have been tested in ALS patients with modest positive results regarding efficacy and safety. Clinical application of stem cells in ALS patients was first reported by Janson and colleagues in a pilot study with 3 subjects submitted to intrathecal transplantation of $2.0 \times 10^{7}$ or $1.0 \times 10^{8}$ autologous peripheral blood stem cells (PBSCs) (36). Two patients experienced speech improvement or muscle strength gain for at least 4 months after the procedure. There were no adverse effects or acceleration of the course of disease over the following 12 months, indicating the safety of the method. A study with 20 patients tested a methodological approach aiming to improve the function of upper motoneurons by injecting 2.5-7.5 $\times 10^{5}$ PBSCs into the frontal motor cortex of enrolled subjects. Compared to control group, the median survival time was significantly higher in the treatment arm, which also showed stable score in the ALS Functional Rating Scale Revised (ALSFRS-R) and the Spitzer 
quality of life scale throughout the follow-up period, suggesting a delay in disease progression (37). An additional trial with a cohort of 67 patients confirmed that procedure was well tolerated, safe, and feasible (38).

BM-MCs have also been tested for ALS therapy. A single arm phase I trial conducted in Spain performed autologous BM-MCs transplantation by intraspinal injection in 11 spinal onset ALS patients $(39,40)$. A median of $462 \times 10^{6}$ cells were infused at thoracic level and subjects were followed up for 1 year. Most of the adverse effects reported were mild and transient, and no acceleration in disease progression was observed, as measured by neurological scales and functional respiratory indexes. Polysomnography showed no significant changes in sleep duration, quality, and ventilation after cell injection, suggesting no cortical diaphragmatic pathway dysfunction. Histopathological examination revealed that in the anterior horn of the grafted segments, motoneurons were significantly more numerous and were surrounded by hematopoietic cells, showing no signs of degeneration, suggesting a neurotrophic action of transplanted cells, as observed by the group in previous preclinical study (41). Sharma and colleagues combined intrathecal and intramuscular autologous BM-MCs transplantation in a cohort of 37 patients and compared them to 20 control subjects (42). The survival duration was significantly higher in the group that underwent cell therapy and the majority of the patients reported improvement in speech, swallowing, respiratory capacity, ambulation, and fine motor activities.

The first FDA-approved stem-cell-based trial for ALS ascertained the feasibility and safety of intraspinal injections of NSI-566RSC, human fetal spinal cordderived NSCs, in 15 patients. Initially, 12 patients received 5 unilateral or 10 bilateral lumbar injections $\left(1.0 \times 10^{5}\right.$ cells/injection $)(43,44)$ and then, 5 unilateral cervical injections were performed on 3 new subjects and on 3 who had previously received bilateral lumbar injections $(45,46)$. Additional 15 patients were recruited to phase II trial to test the safety of escalating doses of NSCs $\left(2.0-16.0 \times 10^{6}\right)(47)$. In general, procedure and doses were well tolerated and many of the adverse events were attributed to the immunosuppressant drugs. A similar methodological approach was used in a phase I clinical study conducted in Italy, with 18 spinal onset ALS patients $(48,49)$. In this case, neural progenitors were isolated from the forebrain of miscarried fetuses. According to ALSFRS-R scores, there was a significant but transient functional improvement within the first 4 months after transplantation. Although these trials demonstrate NSCs safety and some possible efficacy indicators, the use of these cells is often related to ethical and moral concerns and requires an immunosuppressive regimen, which can modify the effect of therapy.

BM-MSCs are among the main cell types used in clinical trials for ALS. Mazzini and collaborators performed two phase I trials with 9 and 10 patients, respectively, to assess the safety of intraspinal transplantation of autologous BM-MSCs $(50,51)$. Different doses ranging from 7.0 to $152.0 \times 10^{6}$ cells were injected into thoracic spinal cord segments and patients were monitored every 3 months until death. The results of long-term follow-up of the 19 patients confirmed that procedure was safe and feasible, despite the absence of clinical benefits (52). Different groups have shown that intrathecal transplantation of autologous BM-MSCs was also feasible and well tolerated $(53,54)$. A phase I trial conducted in the Republic of Korea with 7 patients demonstrated the safety of two repeated BM-MSCs intrathecal injections $\left(1.0 \times 10^{6}\right.$ cells/Kg/injection) (55) and the efficacy was tested in 
a subsequent phase II study with 64 subjects (56). Changes in the ALSFRS-R scores showed that cell therapy was effective in delaying disease progression, and CSF analysis revealed a significant increase in the levels of anti-inflammatory cytokines as well as a reduction in proinflammatory ones after cell injections. Based on these studies, the Korean government approved in 2015 the use of autologous BM-MSCs for the treatment of ALS, becoming the first country in the world to license the commercialization of a stem cell therapy for the disease. Some studies have also combined intrathecal and intravenous or intramuscular administration of BM-MSCs in an attempt to maximize the possible therapeutic benefits and demonstrated a stabilization of the disease or a reduction in progression speed (57-60). Transplantation of MSCs derived from other sources such as adipose tissue and umbilical cord Wharton's jelly have also been shown to be safe and well tolerated $(61,62)$.

Despite the encouraging results obtained so far, further randomized controlled trials with large sample sizes are needed to ascertain the efficacy of cell types, doses, and delivery sites/methods so reliable and reproducible therapeutic regimens can be standardized. Stem cell-based clinical trials for ALS are summarized in Table 1.

\section{MODELLING ALS IN VITRO WITH INDUCED PLURIPOTENT STEM CELLS}

Animal models have contributed enormously to the understanding of ALS pathophysiological mechanisms (63). However, transgenic animal models represent only a small fraction of familial ALS patients, and about $90 \%$ of cases are considered sporadic, without a known genetic component directly associated with the development of the disease. Although motoneuron death is always the final outcome, different molecular pathways can be involved in this degenerative process, depending on the patient's genetic background (64). The lack of variability in preclinical research could explain why therapies with promising results constantly fail or show just modest efficacy results in clinical trials. Therefore, more representative ALS preclinical models, especially for the sporadic form of the disease, are urgently needed.

In 2006, a breakthrough advance in the stem cell field was reported by the Japanese scientists Takahashi and Yamanaka - the genetic reprogramming of adult mice cells into embryonic-like pluripotent stem cells, called iPSCs (65). In the following year, the same feat was achieved with human cells (66). Through this revolutionary technology, it became possible to obtain stem cells capable of differentiating into virtually any cell type from adult somatic cells such as skin, or peripheral blood cells, or even urine (Figure 2).

In 2008, the first iPSCs were derived from an ALS patient, an 82-years old woman carrying a rare mutation in SOD1 gene. Remarkably, the iPSCs could be differentiated in motoneurons and astrocytes, the two neural cells mainly related to ALS pathology. Differentiated cells carried the same mutation from the donor patient, proving it was possible to reproduce in vitro a genetic profile for which, until then, no study model was available (67). Over the past 15 years, iPSCs have been derived from familial and sporadic ALS patients, with different genotypes, 


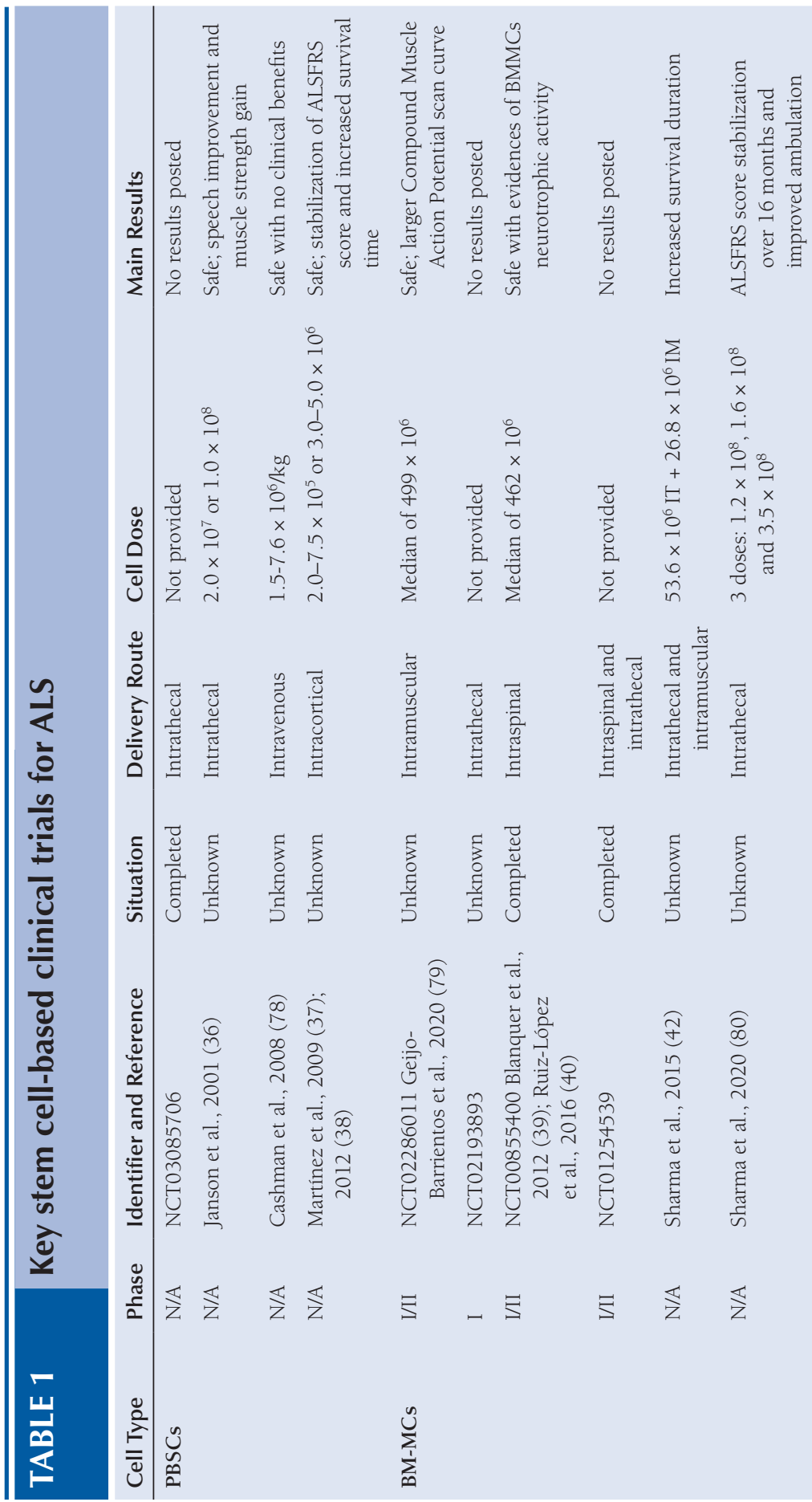




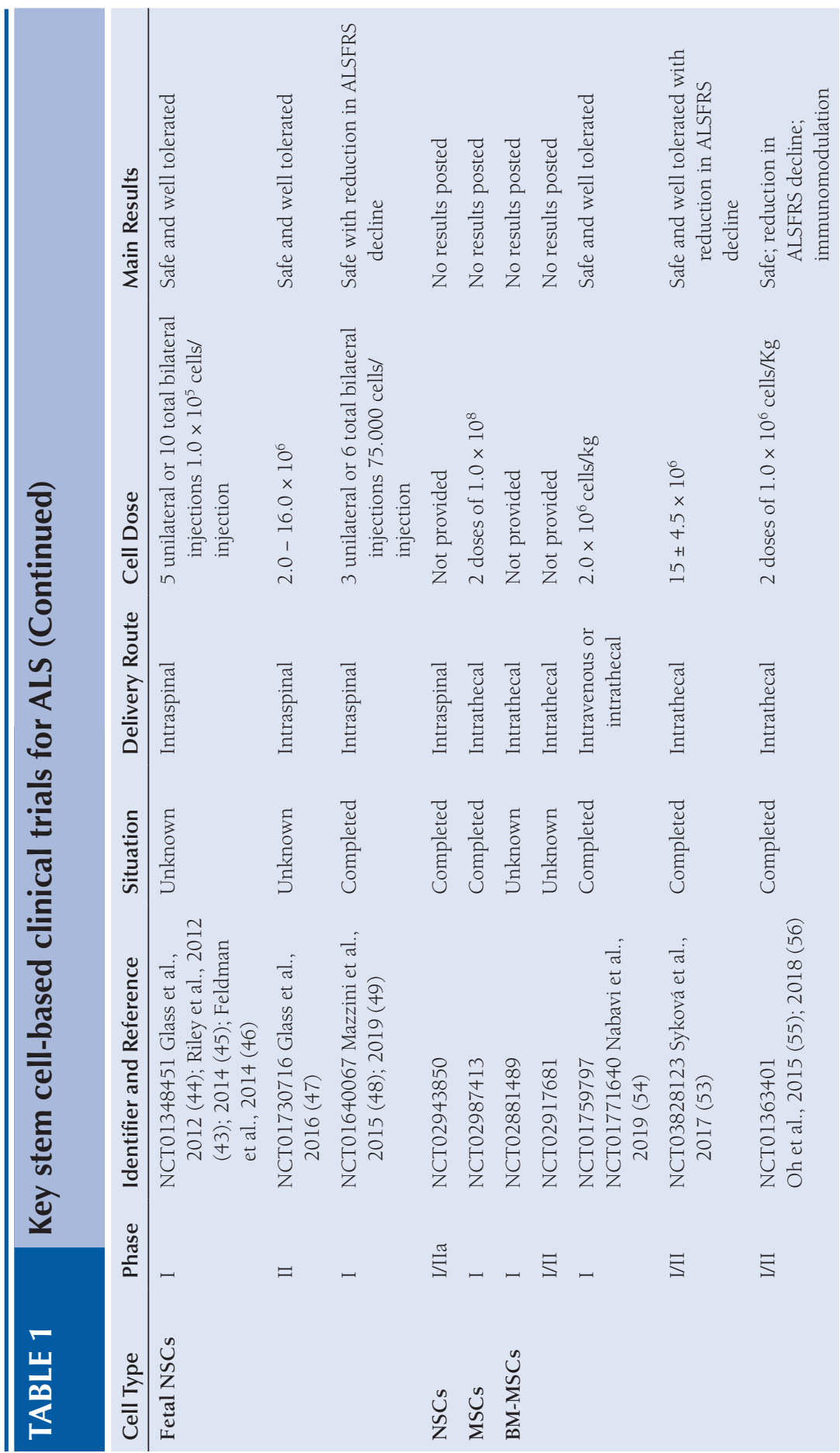




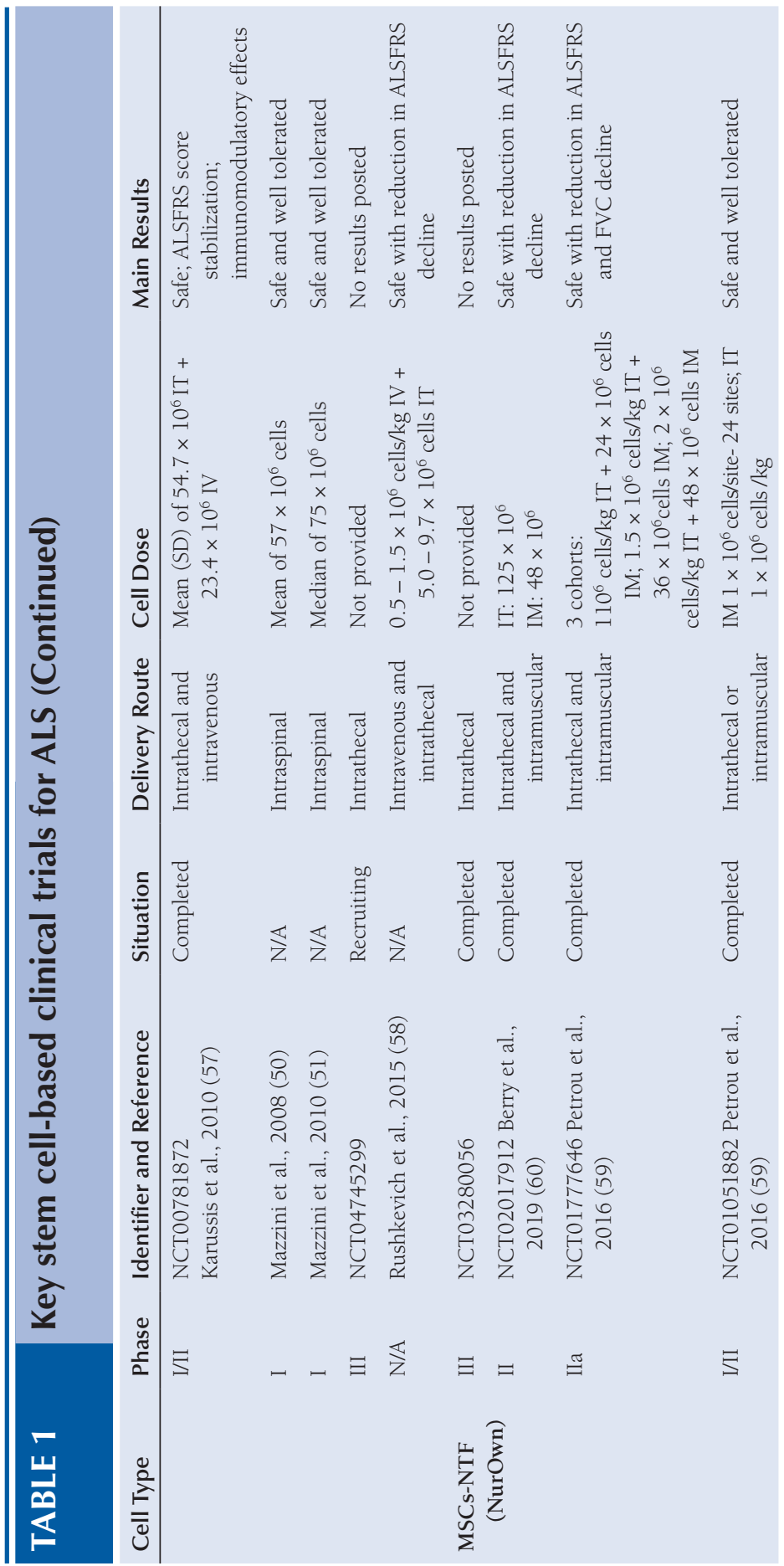




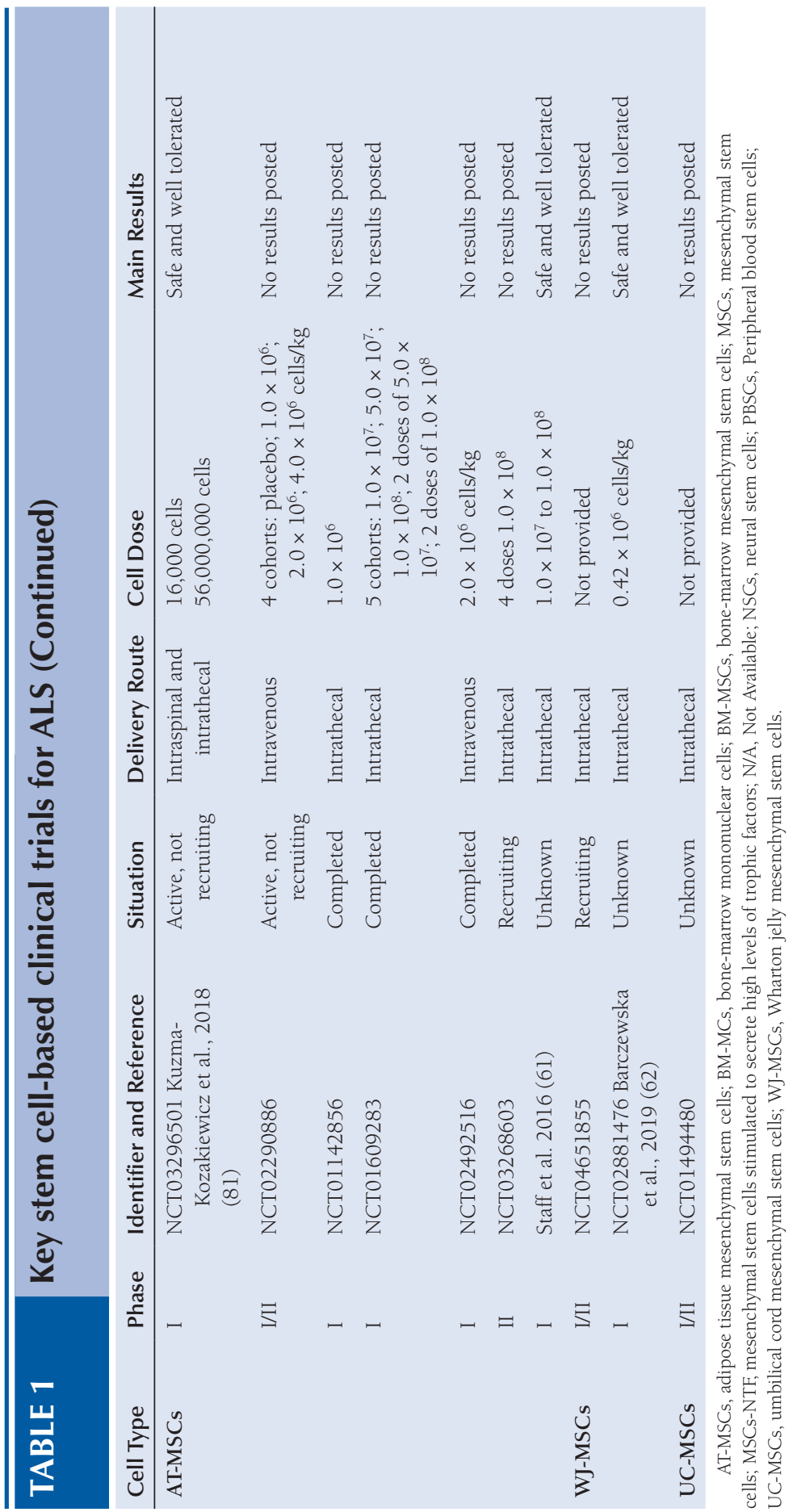




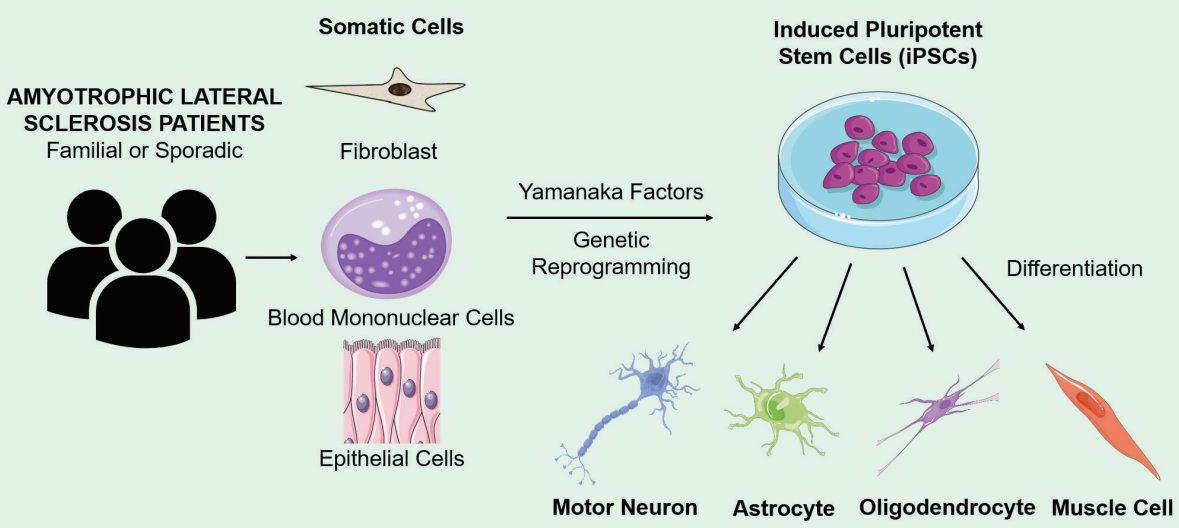

Figure 2. iPSCs can be derived from patient's somatic cells and differentiated in motoneurons, glial cells and muscle fibers, to study ALS pathologic mechanisms in vitro. iPSC-derived cell can also be used in drug screenings and possibly in future cell replacement therapies. Created using https://smart.servier.com/.

and differentiated into cells of interest for the study of the disease, such as motoneurons, astrocytes, oligodendrocytes, and skeletal muscle cells. In these differentiated cells, several important phenotypic alterations were found, which has contributed enormously to the understanding of the pathological mechanisms of the disease. Among the most frequent and relevant findings in motoneurons differentiated from ALS iPSCs are reduction in viability, the presence of intracellular protein aggregates, changes in the electrophysiological properties and mitochondrial function and dynamics (68). Interestingly, several of these features are also present in post-mortem neural tissue from ALS patients. An important ALS histopathological marker is the presence of TDP-43 protein aggregates in spinal cord and motor cortex, and similar aggregates are also consistently found in ALS iPSCsderived motoneurons (69). These findings corroborate the value of iPSCs as an important tool for ALS modelling.

However, the use of iPSCs and iPSCs-derived differentiated neural cells as an in vitro preclinical ALS model has also important limitations. There is still great variability among the phenotypic changes found in motoneurons differentiated from iPSCs by different research groups. Motoneurons harboring different SOD1 mutations, for example, have opposite electrophysiological profiles: while motoneurons with the A4V mutation show hyperexcitability, motoneurons with the D90A and R115G mutations are hypoexcitable and have impaired spontaneous activity $(70,71)$. These contradictory results may be a consequence of using different protocols for iPSCs differentiation, emphasizing the importance of using standardized protocols in the future. Furthermore, ALS-associated mutations are related to different onset age and disease progression. Thus, neural cells differentiated from iPSCs of patients with late onset and/or slow disease progression may need a longer maturation time in vitro to show relevant phenotypic alterations (69). Different strategies are being tested to overcome this limitation. 
Pharmacological agents can be used to accelerate cell maturation process. One of these agents is progerin, a truncated protein produced by patients with HutchinsonGilford syndrome, whose main characteristic is premature aging. Progerin has already been used in iPSCs derived from patients with aging-associated degenerative diseases, such as Parkinson's Disease, successfully accelerating in vitro appearance of cellular features of the disease (72). Thus, although not yet tested in ALS iPSCs, the use of this drug can be a useful tool in ALS modeling as well. Alternatively, ALS iPSCs-derived neural cells seem to be more sensitive to different types of stressors that can be used to speed up phenotypic alterations onset in vitro (73).

In a translational perspective, the use of cells differentiated from ALS iPSCs could be a useful platform for screening new drugs and therapies, stratifying responsive patients according to their genetic profile. Several drugs with therapeutic potential have already been tested in ALS iPSC-derived neural cells. The FDA-approved antiparkinsonian drug Ropinirole performed well in in vitro studies, but just in cell lines harboring SOD1 mutations, an important indicative that some pharmacological therapies can be effective only in a specific fraction of ALS patients (69). However, other drugs, such as Bosutinib, originally used for chronic myeloid leukemia, seems to be effective for a broader number of patients; this drug improved motoneuron survival in cell lines derived from patients with mutations in TARDBP and C9orf72 genes, as well as from sporadic patients (74). Bosutinib is now being tested in a clinical trial with ALS patients (75).

Finally, therapies using iPSCs-differentiated neural cells are promising possibilities. iPSCs-derived dopaminergic neurons have recently been transplanted to a Parkinson's patient, with encouraging results (76). However, in ALS, it is necessary for the new motoneuron to expand its axon to the correct target site in the musculoskeletal system, a complicated task, leaving iPSCs-based motoneuron replacement therapies still a hope for the future. Transplantation of iPSCs-derived astrocytes, however, is an easier and interesting approach. This possibility has already been tested in a mouse model, and animals submitted to human iPSCsderived glial progenitors transplantation into spinal cord had an extension in their lifespan (77).

\section{CONCLUSION}

Preclinical studies and clinical trials indicate that cell therapy is a hopeful therapeutic alternative to ALS patients. However, further studies are required to determine ideal cells candidate, doses, and delivery routes. The great heterogeneity in ALS clinical and genetic presentation also makes it difficult to standardize a unique therapeutic protocol for cell transplantation. In this context, iPSCs-derived cells emerge as a promising tool for the optimization of clinical trials, helping to stratify patients and design effective personalized therapies.

Acknowledgment: We thank the grants that supported this work: CNPq/MS/ SCTIE/DECIT (467337/2014 and 409960/2013-6) and Institutos Nacionais de Ciência e Tecnologia (INCT; 465656/2014-5). R Mendez-Otero received also funding from CNPq and FAPERJ. JF Vasques, RGJ Gonçalves and F Gubert received fellowships from FAPERJ. LCT Pinheiro received fellowship from CNPq. 
Conflict of interest: The authors declare no potential conflict of interest with respect to research, authorship and/or publication of this chapter.

Copyright and permission statement: To the best of our knowledge, the materials included in this chapter do not violate copyright laws. All original sources have been appropriately acknowledged and/or referenced. Where relevant, appropriate permissions have been obtained from the original copyright holder(s).

\section{REFERENCES}

1. Philips T, Robberecht W. Neuroinflammation in amyotrophic lateral sclerosis: role of glial activation in motor neuron disease. Lancet Neurol. 2011;10(3):253-63. https://doi.org/10.1016/ S1474-4422(11)70015-1

2. Jaiswal MK. Riluzole and edaravone: A tale of two amyotrophic lateral sclerosis drugs. Med Res Rev. 2019;39(2):733-748. https://doi.org/10.1002/med.21528

3. Saeedi P, Halabian R, Fooladi AAI. A revealing review of mesenchymal stem cells therapy, clinical perspectives and Modification strategies. Stem Cell Investig. 2019;6:34. https://doi.org/10.21037/ sci.2019.08.11

4. Charif N, Li YY, Targa L, Zhang L, Ye JS, Li YP, et al. Aging of bone marrow mesenchymal stromal/stem cells: Implications on autologous regenerative medicine. Bio-med Mater Eng. 2017;28(s1):S57-63. https://doi.org/10.3233/BME-171624

5. Ende N, Weinstein F, Chen R, Ende M. Human umbilical cord blood effect on sod mice (amyotrophic lateral sclerosis). Life Sci. 2000;67(1):53-9. https://doi.org/10.1016/S0024-3205(00)00602-0

6. Corti S, Locatelli F, Donadoni C, Guglieri M, Papadimitriou D, Strazzer S, et al. Wild-type bone marrow cells ameliorate the phenotype of SODl-G93A ALS mice and contribute to CNS, heart and skeletal muscle tissues. Brain. 2004;127(Pt 11):2518-32. https://doi.org/10.1093/brain/awh273

7. Solomon JN, Lewis CB, Ajami B, Corbel SY, Rossi FMV, Krieger C. Origin and distribution of bone marrow-derived cells in the central nervous system in a mouse model of amyotrophic lateral sclerosis. Glia. 2006;53(7):744-53. https://doi.org/10.1002/glia.20331

8. Gubert F, Santiago MF. Prospects for bone marrow cell therapy in amyotrophic lateral sclerosis: how far are we from a clinical treatment? Neural Regen Res. 2016;11(8):1216-9. https://doi. org/10.4103/1673-5374.189167

9. Garbuzova-Davis S, Sanberg CD, Kuzmin-Nichols N, Willing AE, Gemma C, Bickford PC, et al. Human Umbilical Cord Blood Treatment in a Mouse Model of ALS: Optimization of Cell Dose. PLoS One. 2008;3(6):e2494. https://doi.org/10.1371/journal.pone.0002494

10. Garbuzova-Davis S, Rodrigues MCO, Mirtyl S, Turner S, Mitha S, Sodhi J, et al. Multiple Intravenous Administrations of Human Umbilical Cord Blood Cells Benefit in a Mouse Model of ALS. PLoS One. 2012;7(2):e31254. https://doi.org/10.1371/journal.pone.0031254

11. Bigini P, Veglianese P, Andriolo G, Cova L, Grignaschi G, Caron I, et al. Intracerebroventricular Administration of Human Umbilical Cord Blood Cells Delays Disease Progression in Two Murine Models of Motor Neuron Degeneration. Rejuvenation Res. 2011;14(6):623-39. https://doi. org/10.1089/rej.2011.1197

12. Gubert F, Decotelli AB, Bonacossa-Pereira I, Figueiredo FR, Zaverucha-do-Valle C, TovarMoll F, et al. Intraspinal bone-marrow cell therapy at pre- and symptomatic phases in a mouse model of amyotrophic lateral sclerosis. Stem Cell Res Ther. 2016;7:41. https://doi.org/10.1186/ s13287-016-0293-4

13. Gubert F, Bonacossa-Pereira I, Decotelli AB, Furtado M, Vasconcelos-dos-Santos A, Mendez-Otero $\mathrm{R}$, et al. Bone-marrow mononuclear cell therapy in a mouse model of amyotrophic lateral sclerosis: Functional outcomes from different administration routes. Brain Res. 2019;1712:73-81. https://doi. org/10.1016/j.brainres.2019.02.003 
14. Martínez-Muriana A, Pastor D, Mancuso R, Rando A, Osta R, Martínez S, et al. Combined intramuscular and intraspinal transplant of bone marrow cells improves neuromuscular function in the SOD1G93A mice. Stem Cell Res Ther. 2020;11(1):53. https://doi.org/10.1186/s13287-020-1573-6

15. Pittenger MF, Mackay AM, Beck SC, Jaiswal RK, Douglas R, Mosca JD, et al. Multilineage Potential of Adult Human Mesenchymal Stem Cells. Science. 1999;284(5411):143-7. https://doi.org/10.1126/ science.284.5411.143

16. Dominici M, Blanc KL, Mueller I, Slaper-Cortenbach I, Marini F, Krause D, et al. Minimal criteria for defining multipotent mesenchymal stromal cells. The International Society for Cellular Therapy position statement. Cytotherapy. 2006;8(4):315-7. https://doi.org/10.1080/14653240600855905

17. Stephenson J, Amor S. Modelling amyotrophic lateral sclerosis in mice. Drug Discov Today Dis Model. 2018;25:35-44. https://doi.org/10.1016/j.ddmod.2018.10.001

18. Tovar-y-Romo LB, Ramírez-Jarquín UN, Lazo-Gómez R, Tapia R. Trophic factors as modulators of motor neuron physiology and survival: implications for ALS therapy. Front Cell Neurosci. 2014;8:61. https://doi.org/10.3389/fncel.2014.00061

19. Forostyak S, Jendelova P, Kapcalova M, Arboleda D, Sykova E. Mesenchymal stromal cells prolong the lifespan in a rat model of amyotrophic lateral sclerosis. Cytotherapy. 2011;13(9):1036-46. https://doi. org/10.3109/14653249.2011.592521

20. Bursch F, Rath KJ, Sarikidi A, Böselt S, Kefalakes E, Osmanovic A, et al. Analysis of the therapeutic potential of different administration routes and frequencies of human mesenchymal stromal cells in the SODIG93A mouse model of amyotrophic lateral sclerosis. J Tissue Eng Regen Med. 2019;13(4):649-663. https://doi.org/10.1002/term.2846

21. Forostyak S, Homola A, Turnovcova K, Svitil P, Jendelova P, Sykova E. Intrathecal Delivery of Mesenchymal Stromal Cells Protects the Structure of Altered Perineuronal Nets in SOD1 Rats and Amends the Course of ALS. Stem Cells. 2014;32(12):3163-72. https://doi.org/10.1002/stem.1812

22. Kim H, Kim HY, Choi MR, Hwang S, Nam K-H, Kim H-C, et al. Dose-dependent efficacy of ALShuman mesenchymal stem cells transplantation into cisterna magna in SOD1-G93A ALS mice. Neurosci Lett. 2010;468(3):190-4. https://doi.org/10.1016/j.neulet.2009.10.074

23. Boucherie C, Schäfer S, Lavand'homme P, Maloteaux J, Hermans E. Chimerization of astroglial population in the lumbar spinal cord after mesenchymal stem cell transplantation prolongs survival in a rat model of amyotrophic lateral sclerosis. J Neurosci Res. 2009;87(9):2034-46. https://doi.org/10.1002/jnr.22038

24. Zhou C, Zhang C, Zhao R, Chi S, Ge P, Zhang C. Human marrow stromal cells reduce microglial activation to protect motor neurons in a transgenic mouse model of amyotrophic lateral sclerosis. J Neuroinflammation. 2013;10:52. https://doi.org/10.1186/1742-2094-10-52

25. Řehořová M, Vargová I, Forostyak S, Vacková I, Turnovcová K, Skalníková HK, et al. A Combination of Intrathecal and Intramuscular Application of Human Mesenchymal Stem Cells Partly Reduces the Activation of Necroptosis in the Spinal Cord of SODIG93A Rats. Stem Cells Transl Med. 2019;8(6):535-547. https://doi.org/10.1002/sctm.18-0223

26. Boido M, Piras A, Valsecchi V, Spigolon G, Mareschi K, Ferrero I, et al. Human mesenchymal stromal cell transplantation modulates neuroinflammatory milieu in a mouse model of amyotrophic lateral sclerosis. Cytotherapy. 2014;16(8):1059-72. https://doi.org/10.1016/j.jcyt.2014.02.003

27. Sun H, Hou Z, Yang H, Meng M, Li P, Zou Q, et al. Multiple systemic transplantations of human amniotic mesenchymal stem cells exert therapeutic effects in an ALS mouse model. Cell Tissue Res. 2014;357(3):571-82. https://doi.org/10.1007/s00441-014-1903-z

28. Uccelli A, Milanese M, Principato MC, Morando S, Bonifacino T, Vergani L, et al. Intravenous Mesenchymal Stem Cells Improve Survival and Motor Function in Experimental Amyotrophic Lateral Sclerosis. Mol Med. 2012;18(1):794-804. https://doi.org/10.2119/molmed.2011.00498

29. Marconi S, Bonaconsa M, Scambi I, Squintani GM, Rui W, Turano E, et al. Systemic treatment with adipose-derived mesenchymal stem cells ameliorates clinical and pathological features in the amyotrophic lateral sclerosis murine model. Neuroscience. 2013;248:333-43. https://doi.org/10.1016/j. neuroscience.2013.05.034

30. Terashima T, Kobashi S, Watanabe Y, Nakanishi M, Honda N, Katagi M, et al. Enhancing the Therapeutic Efficacy of Bone Marrow-Derived Mononuclear Cells with Growth Factor-Expressing Mesenchymal Stem Cells for ALS in Mice. iScience. 2020;23(11):101764. https://doi.org/10.1016/j. isci.2020.101764 
31. Xu L, Yan J, Chen D, Welsh AM, Hazel T, Johe K, et al. Human Neural Stem Cell Grafts Ameliorate Motor Neuron Disease in SOD-1 Transgenic Rats. Transplantation. 2006;82(7):865-75. https://doi. org/10.1097/01.tp.0000235532.00920.7a

32. López-González R, Velasco I. Therapeutic Potential of Motor Neurons Differentiated from Embryonic Stem Cells and Induced Pluripotent Stem Cells. Arch Med Res. 2012;43(1):1-10. https://doi. org/10.1016/j.arcmed.2012.01.007

33. Klein SM, Behrstock S, McHugh J, Hoffmann K, Wallace K, Suzuki M, et al. GDNF Delivery Using Human Neural Progenitor Cells in a Rat Model of ALS. Hum Gene Ther. 2005;16(4):509-21. https:// doi.org/10.1089/hum.2005.16.509

34. Suzuki M, McHugh J, Tork C, Shelley B, Klein SM, Aebischer P, et al. GDNF Secreting Human Neural Progenitor Cells Protect Dying Motor Neurons, but Not Their Projection to Muscle, in a Rat Model of Familial ALS. PLoS One. 2007;2(8):e689. https://doi.org/10.1371/journal.pone.0000689

35. Thomsen GM, Avalos P, Ma AA, Alkaslasi M, Cho N, Wyss L, et al. Transplantation of Neural Progenitor Cells Expressing Glial Cell Line-Derived Neurotrophic Factor into the Motor Cortex as a Strategy to Treat Amyotrophic Lateral Sclerosis. Stem Cells. 2018;36(7):1122-1131. https://doi.org/10.1002/ stem. 2825

36. Janson CG, Ramesh TM, During MJ, Leone P, Heywood J. Human Intrathecal Transplantation of Peripheral Blood Stem Cells in Amyotrophic Lateral Sclerosis. J Hematother Stem Cell Res. 2001;10(6):913-5. https://doi.org/10.1089/152581601317211015

37. Martinez HR, Gonzalez-Garza MT, Moreno-Cuevas JE, Caro E, Gutierrez-Jimenez E, Segura JJ. Stemcell transplantation into the frontal motor cortex in amyotrophic lateral sclerosis patients. Cytotherapy. 2009;11(1):26-34. https://doi.org/10.1080/14653240802644651

38. Martínez HR, Molina-LopezJF, González-Garza MT, Moreno-CuevasJE, Caro-Osorio E, Gil-Valadez A, et al. Stem cell transplantation in amyotrophic lateral sclerosis patients: methodological approach, safety, and feasibility. Cell Transplant. 2012;21(9):1899-907. https://doi.org/10.3727/096368911X582769

39. Blanquer M, Moraleda JM, Iniesta F, Gómez-Espuch J, Meca-Lallana J, Villaverde R, et al. Neurotrophic Bone Marrow Cellular Nests Prevent Spinal Motoneuron Degeneration in Amyotrophic Lateral Sclerosis Patients: A Pilot Safety Study. Stem Cells. 2012;30(6):1277-85. https://doi.org/10.1002/ stem. 1080

40. Ruiz-López FJ, Guardiola J, Izura V, Gómez-Espuch J, Iniesta F, Blanquer M, et al. Breathing pattern in a phase I clinical trial of intraspinal injection of autologous bone marrow mononuclear cells in patients with amyotrophic lateral sclerosis. Respir Physiol Neurobiol. 2016;221:54-8. https://doi. org/10.1016/j.resp.2015.11.007

41. Cabanes C, Bonilla S, Tabares L, Martínez S. Neuroprotective effect of adult hematopoietic stem cells in a mouse model of motoneuron degeneration. Neurobiol Dis. 2007;26(2):408-18. https://doi. org/10.1016/j.nbd.2007.01.008

42. Sharma AK, Sane HM, Paranjape AA, Gokulchandran N, Nagrajan A, D'sa M, et al. The effect of autologous bone marrow mononuclear cell transplantation on the survival duration in Amyotrophic Lateral Sclerosis - a retrospective controlled study. Am J Stem Cells. 2015;4(1):50-65.

43. Riley J, Federici T, Polak M, Kelly C, Glass J, Raore B, et al. Intraspinal Stem Cell Transplantation in Amyotrophic Lateral SclerosisA Phase I Safety Trial, Technical Note, and Lumbar Safety Outcomes. Neurosurgery. 2012;71(2):405-16. https://doi.org/10.1227/NEU.0b013e31825ca05f

44. Glass JD, Boulis NM, Johe K, Rutkove SB, Federici T, Polak M, et al. Lumbar Intraspinal Injection of Neural Stem Cells in Patients with Amyotrophic Lateral Sclerosis: Results of a Phase I Trial in 12 Patients. Stem Cells. 2012;30(6):1144-51. https://doi.org/10.1002/stem.1079

45. Riley J, Glass J, Feldman EL, Polak M, Bordeau J, Federici T, et al. Intraspinal Stem Cell Transplantation in Amyotrophic Lateral Sclerosis: A Phase I Trial, Cervical Microinjection, and Final Surgical Safety Outcomes. Neurosurgery. 2014;74(1):77-87. https://doi.org/10.1227/NEU.0000000000000156

46. Feldman EL, Boulis NM, Hur J, Johe K, Rutkove SB, Federici T, et al. Intraspinal neural stem cell transplantation in amyotrophic lateral sclerosis: Phase 1 trial outcomes. Ann Neurol. 2014;75(3):363-73. https://doi.org/10.1002/ana.24113

47. Glass JD, Hertzberg VS, Boulis NM, Riley J, Federici T, Polak M, et al. Transplantation of spinal cordderived neural stem cells for ALS: Analysis of phase 1 and 2 trials. Neurology. 2016;87(4):392-400. https://doi.org/10.1212/WNL.0000000000002889 
48. Mazzini L, Gelati M, Profico DC, Sgaravizzi G, Pensi MP, Muzi G, et al. Human neural stem cell transplantation in ALS: initial results from a phase I trial. J Transl Med. 2015;13:17.

49. Mazzini L, Gelati M, Profico DC, Sorarù G, Ferrari D, Copetti M, et al. Results from Phase I Clinical Trial with Intraspinal Injection of Neural Stem Cells in Amyotrophic Lateral Sclerosis: A Long-Term Outcome. Stem Cells Transl Med. 2019;8(9):887-897. https://doi.org/10.1002/sctm.18-0154

50. Mazzini L, Mareschi K, Ferrero I, Vassallo E, Oliveri G, Nasuelli N, et al. Stem cell treatment in Amyotrophic Lateral Sclerosis. J Neurol Sci. 2008;265(1-2):78-83. https://doi.org/10.1016/j. jns.2007.05.016

51. Mazzini L, Ferrero I, Luparello V, Rustichelli D, Gunetti M, Mareschi K, et al. Mesenchymal stem cell transplantation in amyotrophic lateral sclerosis: A Phase I clinical trial. Exp Neurol. 2010;223(1): 229-37. https://doi.org/10.1016/j.expneurol.2009.08.007

52. Mazzini L, Mareschi K, Ferrero I, Miglioretti M, Stecco A, Servo S, et al. Mesenchymal stromal cell transplantation in amyotrophic lateral sclerosis: a long-term safety study. Cytotherapy. 2012;14(1): 56-60. https://doi.org/10.3109/14653249.2011.613929

53. Syková E, Rychmach P, Drahorádová I, Konrádová Ši, Růžičková K, Voříšek I, et al. Transplantation of Mesenchymal Stromal Cells in Patients with Amyotrophic Lateral Sclerosis: Results of Phase I/Ila Clinical Trial. Cell Transplant. 2017;26(4):647-58. https://doi.org/10.3727/096368916X693716

54. Nabavi SM, Arab L, Jarooghi N, Bolurieh T, Abbasi F, Mardpour S, et al. Safety, Feasibility of Intravenous and Intrathecal Injection of Autologous Bone Marrow Derived Mesenchymal Stromal Cells in Patients with Amyotrophic Lateral Sclerosis: An Open Label Phase I Clinical Trial. Cell J. 2019;20(4):592-598.

55. Oh K-W, Moon C, Kim HY, Oh S, Park J, Lee JH, et al. Phase I Trial of Repeated Intrathecal Autologous Bone Marrow-Derived Mesenchymal Stromal Cells in Amyotrophic Lateral Sclerosis. Stem Cells Transl Med. 2015;4(6):590-7. https://doi.org/10.5966/sctm.2014-0212

56. Oh K, Noh M, Kwon M, Kim HY, Oh S, Park J, et al. Repeated Intrathecal Mesenchymal Stem Cells for Amyotrophic Lateral Sclerosis. Ann Neurol. 2018;84(3):361-373. https://doi.org/10.1002/ ana.25302

57. Karussis D, Karageorgiou C, Vaknin-Dembinsky A, Gowda-Kurkalli B, Gomori JM, Kassis I, et al. Safety and Immunological Effects of Mesenchymal Stem Cell Transplantation in Patients With Multiple Sclerosis and Amyotrophic Lateral Sclerosis. Arch Neurol. 2010;67(10):1187-94. https:// doi.org/10.1001/archneurol.2010.248

58. Rushkevich YuN, Kosmacheva SM, Zabrodets GV, Ignatenko SI, Goncharova NV, Severin IN, et al. The Use of Autologous Mesenchymal Stem Cells for Cell Therapy of Patients with Amyotrophic Lateral Sclerosis in Belarus. Bull Exp Biol Med. 2015;159(4):576-81. https://doi.org/10.1007/ s10517-015-3017-3

59. Petrou P, Gothelf Y, Argov Z, Gotkine M, Levy YS, Kassis I, et al. Safety and Clinical Effects of Mesenchymal Stem Cells Secreting Neurotrophic Factor Transplantation in Patients With Amyotrophic Lateral Sclerosis: Results of Phase 1/2 and 2a Clinical Trials. Jama Neurol. 2016;73(3):1-8. https://doi. org/10.1001/jamaneurol.2015.4321

60. Berry JD, Cudkowicz ME, Windebank AJ, Staff NP, Owegi M, Nicholson K, et al. NurOwn, phase 2, randomized, clinical trial in patients with ALS: Safety, clinical, and biomarker results. Neurology. 2019;93(24):e2294-e2305. https://doi.org/10.1212/WNL.0000000000008620

61. Staff NP, Madigan NN, Morris J, Jentoft M, Sorenson EJ, Butler G, et al. Safety of intrathecal autologous adipose-derived mesenchymal stromal cells in patients with ALS. Neurology. 2016;87(21):22302234. https://doi.org/10.1212/WNL.0000000000003359

62. Barczewska M, Grudniak M, Maksymowicz S, Siwek T, Ołdak T, Jezierska-Woźniak K, et al. Safety of intrathecal injection of Wharton's jelly-derived mesenchymal stem cells in amyotrophic lateral sclerosis therapy. Neural Regen Res. 2019;14(2):313-318. https://doi.org/10.4103/1673-5374.243723

63. Lutz C. Mouse models of ALS: Past, present and future. Brain Res. 2018;1693(Pt A):1-10. https://doi. org/10.1016/j.brainres.2018.03.024

64. Jiang J, Zhu Q, Gendron TF, Saberi S, McAlonis-Downes M, Seelman A, et al. Gain of Toxicity from ALS/FTD-Linked Repeat Expansions in C9ORF72 Is Alleviated by Antisense Oligonucleotides Targeting GGGGCC-Containing RNAs. Neuron. 2016;90(3):535-50. https://doi.org/10.1016/j. neuron.2016.04.006 
65. Takahashi K, Yamanaka S. Induction of Pluripotent Stem Cells from Mouse Embryonic and Adult Fibroblast Cultures by Defined Factors. Cell. 2006;126(4):663-76. https://doi.org/10.1016/j. cell.2006.07.024

66. Takahashi K, Tanabe K, Ohnuki M, Narita M, Ichisaka T, Tomoda K, et al. Induction of Pluripotent Stem Cells from Adult Human Fibroblasts by Defined Factors. Cell. 2007;131(5):861-72. https://doi. org/10.1016/j.cell.2007.11.019

67. Dimos JT, Rodolfa KT, Niakan KK, Weisenthal LM, Mitsumoto H, Chung W, et al. Induced Pluripotent Stem Cells Generated from Patients with ALS Can Be Differentiated into Motor Neurons. Science. 2008;321(5893):1218-21. https://doi.org/10.1126/science.1158799

68. Vasques JF, Mendez-Otero R, Gubert F. Modeling ALS using iPSCs: is it possible to reproduce the phenotypic variations observed in patients in vitro? Regen Med. 2020;15(7):1919-1933. https://doi. org/10.2217/rme-2020-0067

69. Fujimori K, Ishikawa M, Otomo A, Atsuta N, Nakamura R, Akiyama T, et al. Modeling sporadic ALS in iPSC-derived motor neurons identifies a potential therapeutic agent. Nat Med. 2018;24(10): 1579-1589. https://doi.org/10.1038/s41591-018-0140-5

70. Wainger BJ, Kiskinis E, Mellin C, Wiskow O, Han SSW, Sandoe J, et al. Intrinsic Membrane Hyperexcitability of Amyotrophic Lateral Sclerosis Patient-Derived Motor Neurons. Cell Rep. 2014;7(1):1-11. https://doi.org/10.1016/j.celrep.2014.03.019

71. Naujock M, Stanslowsky N, Bufler S, Naumann M, Reinhardt P, Sterneckert J, et al. 4-Aminopyridine Induced Activity Rescues Hypoexcitable Motor Neurons from Amyotrophic Lateral Sclerosis PatientDerived Induced Pluripotent Stem Cells. Stem Cells. 2016;34(6):1563-75. https://doi.org/10.1002/ stem. 2354

72. Miller JD, Ganat YM, Kishinevsky S, Bowman RL, Liu B, Tu EY, et al. Human iPSC-Based Modeling of Late-Onset Disease via Progerin-Induced Aging. Cell Stem Cell. 2013;13(6):691-705. https://doi. org/10.1016/j.stem.2013.11.006

73. Sun X, Song J, Huang H, Chen H, Qian K. Modeling hallmark pathology using motor neurons derived from the family and sporadic amyotrophic lateral sclerosis patient-specific iPS cells. Stem Cell Res Ther. 2018;9(1):315. https://doi.org/10.1186/s13287-018-1048-1

74. Imamura K, Izumi Y, Watanabe A, Tsukita K, Woltjen K, Yamamoto T, et al. The Src/c-Abl pathway is a potential therapeutic target in amyotrophic lateral sclerosis. Sci Transl Med. 2017;9(391):eaaf3962. https://doi.org/10.1126/scitranslmed.aaf3962

75. Imamura K, Izumi Y, Banno H, Uozumi R, Morita S, Egawa N, et al. Induced pluripotent stem cellbased Drug Repurposing for Amyotrophic lateral sclerosis Medicine (iDReAM) study: protocol for a phase I dose escalation study of bosutinib for amyotrophic lateral sclerosis patients. BMJ Open. 2019;9(12):e033131. https://doi.org/10.1136/bmjopen-2019-033131

76. Schweitzer JS, Song B, Herrington TM, Park T-Y, Lee N, Ko S, et al. Personalized iPSC-Derived Dopamine Progenitor Cells for Parkinson's Disease. N Engl J Med. 2020;382(20):1926-1932. https:// doi.org/10.1056/NEJMoal915872

77. Kondo T, Funayama M, Tsukita K, Hotta A, Yasuda A, Nori S, et al. Focal Transplantation of Human iPSC-Derived Glial-Rich Neural Progenitors Improves Lifespan of ALS Mice. Stem Cell Reports. 2014;3(2):242-9. https://doi.org/10.1016/j.stemcr.2014.05.017

78. Cashman N, Tan LY, Krieger C, Mädler B, Mackay A, Mackenzie I, et al. Pilot study of granulocyte colony stimulating factor (G-CSF)-mobilized peripheral blood stem cells in amyotrophic lateral sclerosis (ALS). Muscle Nerve. 2008;37(5):620-5. https://doi.org/10.1002/mus.20951

79. Geijo-Barrientos E, Pastore-Olmedo C, De Mingo P, Blanquer M, Gómez Espuch J, Iniesta F, et al. Intramuscular Injection of Bone Marrow Stem Cells in Amyotrophic Lateral Sclerosis Patients: A Randomized Clinical Trial. Front Neurosci. 2020;14:195. https://doi.org/10.3389/fnins.2020.00195

80. Sharma A, Sane H, Paranjape A, Pradhan R, Das R, Biju H, et al. Multiple doses of cell therapy and neurorehabilitation in amyotrophic lateral sclerosis: A case report. Clin Pract. 2020;10(3):1242. https://doi.org/10.4081/cp.2020.1242

81. Kuzma-Kozakiewicz M, Marchel A, Kaminska A, Gawel M, Sznajder J, Figiel-Dabrowska A, et al. Intraspinal Transplantation of the Adipose Tissue-Derived Regenerative Cells in Amyotrophic Lateral Sclerosis in Accordance with the Current Experts' Recommendations: Choosing Optimal Monitoring Tools. Stem Cells Int. 2018;2018:4392017. https://doi.org/10.1155/2018/4392017 
